\title{
Taxonomy and nomenclature of bacteria with clinical and scientific importance: current concepts for pharmacists and pharmaceutical scientists
}

\author{
MÁRIÓ GAJDÁCS \\ ${ }^{1}$ Department of Pharmacodynamics and Biopharmacy, Faculty of Pharmacy, University of Szeged, Szeged, Hungary \\ ${ }^{*}$ Corresponding author: Márió Gajdács \\ Email:gajdacs.mario@pharm.u-szeged.hu
}

Received: 17 October 2019 / Accepted: 1 January 2020

\begin{abstract}
Taxonomy is the science of the classification of various living organisms consisting of three independent, but interrelated disciplines, namely classification, nomenclature and identification. With the advent of molecular biological methods and sequencing, a revolution is currently occurring with regards to the reporting of novel taxa and changes in the taxonomy of already described bacterial species. The applications of taxonomic changes can be broad ranging: they may impact the clinical care of patients, through variations in choosing the appropriate antimicrobial susceptibility testing standards or data interpretation, or even their clinical relevance and epidemiology. The aim of this paper was to aid healthcare professionals and pharmaceutical scientists to navigate through the 'maze' of bacterial taxonomy, and to aid in finding authentic information regarding the description of taxonomic changes and to present some examples of changes in bacterial taxonomy which have proven to be clinically significant.
\end{abstract}

Keywords: bacteria, taxonomy, nomenclature, identification, molecular, microbiology, educational

\section{Introduction to (bacterial) taxonomy}

Taxonomy (from the greek words taxis=arrangement or order, and nemein=to distribute or govern) is the science of the classification of various living organisms [1,2]. In case of bacteria, taxonomy consists of three independent, but interrelated disciplines, namely classification, nomenclature and identification (sometimes referred to as the 'trinity' of taxonomy) [2]. The most basic taxonomic group (i.e. unit) in bacterial taxonomy is the species, while groups of species are collected into genera (genus), which are then collected into families ( $F a-$ milia), families into orders (Ordo), orders into classes (Classis), classes into phyla (Phylum) and phyla into a domain (or Kingdom, the highest level), however, there are subgroups to these main classifica- tions (see Table I and II for examples). Groups of bacteria at each rank or level have names with endings or suffixes characteristic to that rank or level (Table I) [1-3].

Nevertheless, taxonomic units under species may still be relevant (especially in the case of medically-relevant bacteria), because members among specific species can be distinguished on the basis of certain biological or genetic characteristics: these members may be classified in a sub-group of members, called subspecies [1-3]. An example for this is the differentiation of Camplyobacter species: C. fetus subsp. veneralis is a causative agent of sexually transmitted diseases and miscarriage among cattle, while C. fetus subsp. fetus may cause intrauterine infection in humans [4]. Antigenic characteristics may be another possible way to distinguish subgroups under the threshold of species, called

Table I Example of taxonomic classification for a common Gram-positive, Gram-negative and an atypical pathogen

\begin{tabular}{l|l|l|l}
\hline & Staphylococcus aureus & \multicolumn{2}{l}{ Pseudomonas aeruginosa } \\
\hline Kingdom & Bacteria & Bacteria & Bacteria \\
\hline Phylum & Firmicutes & Proteobacteria & Tenericutes \\
\hline Class & Bacilli & Gammaproteobacteria & Mollicutes \\
\hline Order & Bacillales & Pseudomonadales & Mycoplasmatales \\
\hline Family & Staphylococcaceae & Pseudomonadaceae & Mycoplasmataceae \\
\hline Genus & Staphylococcus & Pseudomonas & Mycoplasma \\
\hline Species & S. aureus & P. aeruginosa & M. pneumoniae \\
\hline
\end{tabular}


serogroups or serovariants [5]. In case of gut bacteria or Enterobacteriaceae (especially important for Salmonella species and Escherichia coli), hundreds of different serovariants may be differentiated, based on the cell wall $(\mathrm{O}$; somatic antigen, based on oligosaccharides), capsule (K, from the German Kapsel or Bacterienkap$\mathrm{sel})$ and flagellar $(\mathrm{H}$; from the German Hauch meaning "breath" or "mist") antigens [6,7]. In fact, this is the basis of the Kauffman-White classification, which was frequently used for routine clinical microbiology and public health purposes for serotyping [8]. Similarly, bacteria may be further characterized based on their disease-causing capacity (pathogenicity) into pathotypes, e.g., extraintestinal-pathogenic E. coli (ExPEC), enteropathogenic E. coli (EPEC), enterotoxin-producing $E$. coli (ETEC), enteroinvasive E. coli (EIEC), enteroaggregative $E$. coli (EAEC), diffusely adherent $E$. coli (DAEC) and so on $[9,10]$.

However, a lot has changed since the first description of taxonomy (Augustin Pyramus de Candolle, 1813), when the available methods for the characterization of bacterial, plant or animal species were very limited [11]. Nowadays, with the advent of molecular biological methods and sequencing, a revolution is currently occurring with regards to the reporting of novel taxa [12]. The description of new bacterial species was further fa-

Table II Characteristics of the current bacterial classification and the number validly published names for each classification level [22]

\begin{tabular}{l|l|r}
\hline \multicolumn{2}{c}{ Taxonomical level } & \multicolumn{1}{c}{ n } \\
\hline Kingdom & Regnum & 1 \\
\hline Subkingdom & Subregnum & 2 \\
\hline Infrakingdom & Infraregnum & 2 \\
\hline Superdivision/Superphyla & Superdivisio & 1 \\
\hline Subdivision/Subphyla & Subdivisio & 9 \\
\hline Superclass & Superclassis & 2 \\
\hline Class & Classis & 106 \\
\hline Subclass & Subclassis & 8 \\
\hline Order & Ordo & 188 \\
\hline Suborder & Subordo & 19 \\
\hline Family & Familia & 399 \\
\hline Subfamily & Subfamilia & 0 \\
\hline Tribe & Tribus & 24 \\
\hline Subtribe & Subtribus & 0 \\
\hline Genus & Genus & 2854 \\
\hline Species & Species & 15626 \\
\hline Subspecies & Subspecies & 586 \\
\hline
\end{tabular}

cilitated by the newfound interest in the characterization of the human microbiome [13]. One of the most important milestones was the launch of the Human Microbiome Project (HMB; the first phase of which was launched in 2007), with the aim of characterize the human gut microbial flora in healthy (physiological) and disease states; the long-term aim of this project was to find causation between human pathologies (e.g., autoimmune disorders, obesity, diabetes, neuropsychiatric disorders, diseases affecting the cardiovascular system) and qualitative/quantitative changes in the microbiome [14-16]. Microbial culturomics (a technique allowing for the culturing of previously unculturable bacterial species by reproducing their natural habitats using complex methods, with the aid of matrix-assisted laser desorption-ionization time-of-flight mass spectrometry [MALDI-TOF MS] and whole-genome sequencing [WGS]) has also resulted in the description of a staggering number of novel taxa [17-19]. Sequencing technologies also had a significant role in the description of the prokaryotic genetic diversity.

Between 1990 and 2000, there was on average 200 novel bacterial species described per year [20]. Owing to these recent developments, the number of validly published genera and species has increased by approximately 50\% since 2004, reducing the percentage of known prokaryotes that have been implicated in animal or human clinical conditions from $\sim 15 \%$ to $10 \%$ [21]. Based on the records of the bacterio.net database, there are currently 19,717 validly published bacterial names and 383 so-called candidate names published (as of $20^{\text {th }}$ of October, 2019) [22]. However, the database of EZBioCloud.net (a freely-accesible database on prokaryotic diversity) contains 81,189 taxa (out of which, $24.89 \%$ has been validly published and $0.51 \%$ are candidate names), 64,416 $16 \mathrm{~S}$ rRNA sequences (a highly conserved, evolutionally-constant region) and 146,704 qualified genomes (as of $9^{\text {th }}$ of August, 2019) [23]. Nonetheless, there are reports estimating that the currently known/described microbiological diversity only represents around $1-5 \%$ of the global prokaryotic diversity [20-21].

Bacterial systematics is a field, which is frequently used synonymously with taxonomy, however, the scope of systematics is much broader, including data on bacterial morphology, physiology, molecular biology and biochemistry, metabolic products, pathogenic potential, ecological niches and epidemiology to characterize, arrange and 
classify bacteria [24]. Systematics became more relevant after the widespread adoption of molecular biological methods, ever higher resolution characterization of bacterial species [25] (Figure 1).

Due to the rapid developments in bacterial taxonomy, both consisting of the description of novel taxa and reclassification of existing bacterial genera to other taxonomical units (e.g., the history of S. maltophilia: it first described as Bacterium booker (1943), later on, it was redesignated as Pseudomonas maltophilia (1958) and Xanthomonas maltophilia (1981); finally, in 1993, the genus Stenotrophomonas was proposed), it is very difficult, if not impossible for researchers, officials, public health microbiologists and healthcare professionals to keep in mind all the accepted or proposed changes [26,27]. However, the importance of correct taxonomy in scientific communication and the diagnostics and therapy of bacterial infections cannot be underestimated [3]. Even if they are not aware of all the changes and the newly introduced species, relevant persons should be able to quickly find them in medical literature, scientific publications or other sources (Web pages or blogs kept up by taxonomists).

There are various resources for pharmaceutical scientists and microbiologists to get informed regarding the recognition of novel bacterial species or describing proposed reclassification of an older species. The official publication prokaryotic taxonomy and source of data regarding these matters in the International Journal of Systematic and Evolutionary Microbiology (IJSEM); the main aim and role of this publication is to report the description of new taxa or the reclassification of existing spe-

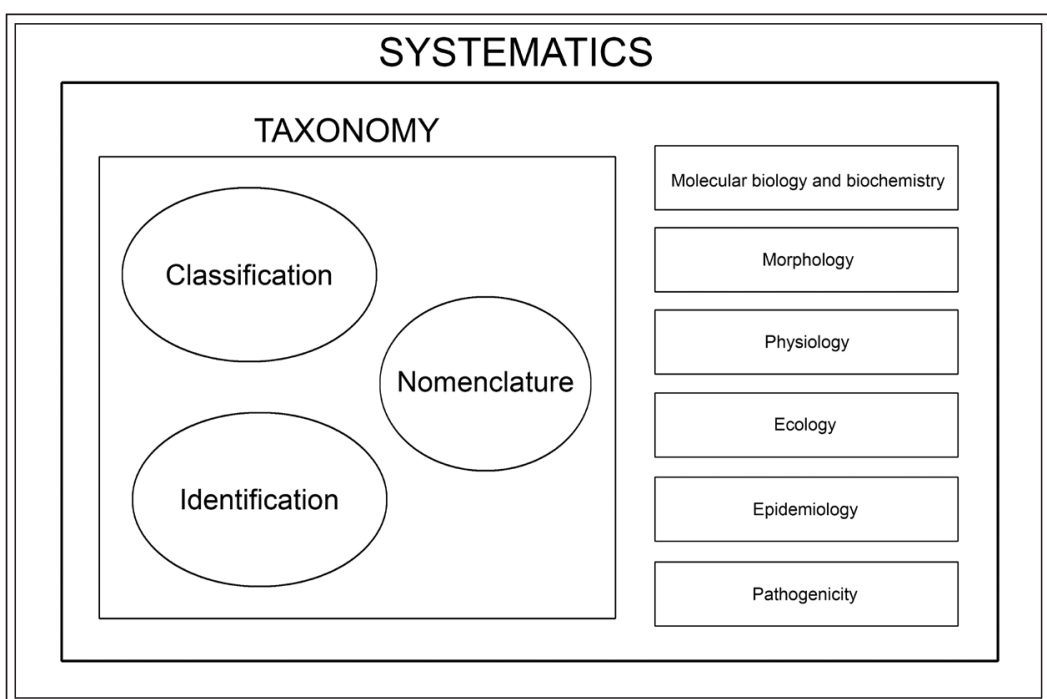

Figure 1 Relationship of the field of taxonomy and bacterial systematics cies [28]. The rules associated with the proposal of new bacterial taxa were described in the Bacteriological Code (1990), which was updated though the publication of the Taxonomic Outline of the Bacteria and Archaea (TOBA; 2006) [29,30]. Additional amendments to these rules are generally published in IJSEM. The proposed new species and species names (candidate) are to be submitted to the Editorial Office of IJSEM for evaluation, with the suffix nova (genus nova, species nova). The new taxonomy and nomenclature can only be considered as official, if the Editorial Board of IJSEM and the International Committee on Systematics of Prokaryotes (ICSP) both approve the submission [21]. If approved, the proposed name receives the approved state (valid name), which is formalized by the certificate of approval awarded by the IJSEM and ICSP [21,28]. However, once these taxa are on the approved lists, they may still be subject to reclassification, based on the designation of synonyms or due to a transfer to another genus. The validation of a new taxa is finalized if designated type strains of the species are deposited into internationally-recognized culture collections (e.g., American Type Culture Collection [ATCC], Asian Bacterial Bank [ABB], Anaerobe Reference Laboratory, Helsinki Collection [AHN], Culture Collection of Switzerland [CCOS], Collection de l'Institut Pasteur [CIP], United Kingdom National Culture Collection [UKNCC]) at least in two separate countries [31].

The Antoine van Leeuwenhoek Journal of Microbiology has become the second main journal in this field in the recent years, reporting on $>100$ new candidate species per year, since 2014 [32]. In addition, several other journals with interests in microbiology/infectious diseases may be vehicles in reporting novel taxa, including but not limited to: Systematic and Applied Microbiology, Journal of Medical Microbiology, Current Microbiology, Clinical Microbiology and Infection, Diagnostic Microbiology and Infectious Disease, Anaerobe, Infection, Genetics and Evolution, Journal of Antimicrobial Chemotherapy, Emerging Microbes and Infections, New Microbes and New Infections, Microbiology and Immunology, Frontiers in Genetics, Frontiers in Microbiology, Archives of Microbiology, MicrobiologyOpen, Standards in Genomic Sci- 
ences, Acta Pathologica Microbiologica et Immunologica Scandinavica (APMIS), Zentralblatt für Bakteriologie, Research in Microbiology [33]. Nevertheless, it is important to note that for the novel or revised taxa to be validly published (and the study was not submitted to IJSEM), the proposition must be included on an "approved" list in IJSEM. IJSEM publishes papers entitled "List of new names and new combinations previously effectively, but not validly, published" six-to-twelve times per year, which gives a good idea about the momentum of bacterial taxonomy $[21,28,33]$. The proposed taxa that have been previously described in other journals will be footnoted in IJSEM.

\section{What is in a name: nomenclature in bacteriology}

The discipline of nomenclature is mainly concerned with the assignment of names to taxonomic units or groups, on the basis of specific rules [34]. Before a name could be designated for any microorganism, one has to describe its biological characteristics (for its future identification), allowing for its classification in the subordinate system, as previously described [1-3]. The origins of nomenclature date back to 1753, when Carl Linnaeus published Species Plantarum, introducing the binomial nomenclature and the currently used classification hierarchy, based on greek-latin terms as the normal system of naming organisms [35]. Species Plantarum (later functioning as the International Code of Botanical Nomenclature [ICBN]) was first set of rules and recommendations of its kind. Because bacteria were once classified among plants, the nomenclature of these microorganisms was subject to the rules of the ICBN until the 1930s, when the bacteriological society has decided on the preparation of an independent code. The International Code of Bacteriological Nomenclature (or Bacteriological Code for short) was first approved in Copenhangen, 1947 [29,30]. The entire framework of naming bacteria is too complex to be described in its entirety, as the Bacteriological Code currently had more than 500 rules and regulations regarding name proposals for novel species names (which are periodically being updated; the updates are published in IJSEM) [36]. As the "intellectual capital" (i.e. available empirical and experimental data) available for the scientists submitting the candidate names for consideration constantly grows, so does the scientific accuracy of the bacterial names. The etymology (the study of the origin and history of words) of bacterial genus/species name is very diverse; here are several examples on the etymology of some bacterial genera:

- Famous microbiologists (or scientists): Rothia (Genevieve D. Roth), Kingella and Elizabethkingia (Elizabeth O. King), Escherichia (Theodor Escherich), Pasterurella (Louis Pasteur), Gaffyka (Georg Theodor A. Gaffky), Burkholderia (W.H. Burkholder), Ehrlichia (Paul Ehrlich), Serratia (Serafino Serrati, physicist)

- Mythological names: Cronobacter (Cronos, a titan), Proteus (Proteus, a prophetic sea-god), Telluria (Tellus, a Roman goddess personifying the Earth)

- Morphological characteristics: Bacillus (rod), Streptococcus (spheres with grape-like organization), Helicobacter (helical-shaped), Campylobacter (curved rod), Clostridium (greek word for spindle)

- Biochemical characteristics: Achromobacter (has no pigment), Acinetobacter (non-motile), Chomobacterium (produces pigment), Anaerococcus (strict anaerobe)

- Geographical (e.g., site of first isolation): Budvicium (Latin name of the city Cěské Budějovice where the bacterium was first isolated), Hafnia (old name for Copenhagen), Orientia (the Orient, the area where the organisms are widely distributed), Sinorhizobium (which lives in a root in China)

- Distribution: Aerococcus (air), Enterococcus (gut), Coprococcus (feces), Leptotrichia (fine hair [of rabbits])

- Disease-causing capability: S. pneumoniae (pneumonia), Vibrio cholerae (cholera: watery diarrhoea), N. meningitidis (meningitis), P. multocida (lethal to many)

- Institutions: Centers for Disease Contol and Prevention (CDC): Cedaceae, Armed Forces Institute of Pathology (AFIP): Apifia

Changes at higher taxonomical levels (e.g., at orders and classes) are obviously much less likely to occur than in lower units, therefore one of the most common conventions on denominations is that the family name is based on the name of the most typical genus (i.e. a type species) in its domain [29-36]. A typical example is the Legionellaceae family, where the most characteristic genera is the one containing the Legionella species, namely L. pneumophila, the causative agent of Legionairre's disease. In contrast, for Enterobacteriaceae, E. coli is considered the type species, but the family 
is not called Escherichiaceae; instead, due to the anatomical localization of most of these bacteria in the gut flora, they are classified in Enterobacteriaceae. Interestingly, the family Enterobacteriaceae contains a genus called Enterobacter, however, if one of the members of this genus would be the type species in the family, it would need to be called Enterobacteraceae [29-37]. The correct writing of bacterial taxonomical designations are also strictly defined by this convention, e.g. names of the species, genera and family are written in italics, however, at higher taxonomical designations, this is not done [29-36].

The use of abbreviations is also common in the literature and the routine clinical practice. Although there are official (defined in the Bacterial Code) three-letter abbreviations for a variety of bacterial genera (e.g., Acp. for Acidophilum, Rsc. for Roseococcus) to ease correspondences regarding anoxygenic phototrophic bacteria, other "real word" examples include mosaic terms derived from names of bacterial groups (e.g., GAS: Group A Streptococcus; ESKAPE: Enterococcus faecium, S. aureus, Klebsiella spp., Acinetobacter baumannii, P. aeruginosa, Enterobacter spp.), therapeutic recommendations (e.g., MRSA: methicillin-resistant $S$. aureus) or public health significance (e.g., MSTM: multidrug-resistant Stenotrophomonas maltophilia, MDRAB: multidrug-resistant A. baumannii) [27, 38-43]. It must be noted that in medicine (especially as far as the clinical microbiologist-physician relationship is concerned), the use of commonly known names is preferred, which are not subject to change (irrespective of taxonomic changes), so that the doctors reading the reports, e.g., of a susceptibility test can comprehend them [29-36].

\section{Laboratory methods used in bacterial taxonomy and identification}

The discipline of classification refers to the act of arranging bacteria into these group or taxa, based on their evolutionary relationships and similarity [44]. In the early days of bacterial taxonomy, the basis of classification was solely on the determination of microscopic morphology and phenotypic characteristics, which could be observed by a light microscope or by organoleptic analysis in liquid or solid media [11]. Later on, this was complemented by the detection of the presence or absence of various enzymes, such as coagulase (differentiates between coagulase positive $S$. aureus and coagulase-negative Staphylococcus species), catalase (among other things, it differentiates between Staphylococcus and Streptococcus species), oxidase (aids in the differentiation of non-fermenting Gram-negative bacteria, e.g., Pseudomonas and Acinetobacter), urease (among other things, it differentiates between Ureaplasma and Mycoplasma species) and the study of the use of different sugars (i.e. their oxidative or fermentative breakdown) [45]. For a very long period of time, these biochemical tests were the mainstay of identification in clinical bacteriology. Identification may be considered as applied taxonomy, during which microbiologists determine whether a particular isolate belongs to a recognized taxon (i.e., genus, species or subspecies) [1-3]. One of the main utilizers of bacterial identification in medicine is the field of clinical microbiology (where bacterial pathogens are identified from various clinical samples to establish the patient's illness and to guide targeted antimicrobial therapy) and public health (the followup of outbreaks caused by bacteria), however, companies involved in pharmaceutical research, biotechnology, forensics are all relevant stakeholders [21].

In the last several decades, pronounced changes were brought about in bacterial taxonomy, due to the introduction of nucleic acid-based and molecular techniques, thus making phenotypic methods less and less relevant [46]. These methods have demonstrated that genotypic/phylogenetic relatedness does not necessary correlate well with phenotypic attributes, such as a Gram-staining pattern, microscopic morphology, oxygen-tolerance or fastidious growth characteristics [47]. These molecular methods include comparison of DNAdenaturation or melting temperatures $\left(T_{m}\right)$, characterization of GC (guanine and cytosine) ratios of bacterial DNA, DNA-DNA and DNA-RNA hybridization, pulse-field gel electrophoresis (PFGE), multi-locus sequence typing (MLST), average nucleotide identity (ANI), MALDI-TOF MS, $16 \mathrm{~S}$ rRNA gene and whole genome sequencing (WGS) and next-generation sequencing (NGS) [48-50]. The use of these methods in increasingly prevalent not only in classification, but also in identification thus, revolutionizing the field of microbiology in the process [48-50]. The prevalence of their use is mainly determined by their accuracy, robustness and their price. Based on the abovementioned methods, two bacteria are considered to be the same species, if their nucleotide sequences are at least $70 \%$ identical, and the difference between their $\mathrm{T}_{\mathrm{m}}$ values is less, than $5 \%$ [47]. The analysis 
of the $\mathrm{GC}$ ratio $(\mathrm{G}+\mathrm{C}$ content) in genomic DNA is also a suitable taxonomic method: the GC ratio is the most variable in prokaryotic genomes (20$80 \%$ ); however, in strains of a specific species, the GC content is shown to be constant. It is basically defined as percentage of the $\mathrm{G}$ and $\mathrm{C}$ amino nucleotides in the bacterial genome, which was frequently used for the division of various bacterial genera (e.g., staphylococci and micrococci highly resemble each other, based on phenotypic and biochemical characteristics, however, the difference in their GC ratios has been shown to be pronounced [ $\sim 30-40 \%$ vs. $\sim 65-75 \%]$ ] [51]. DNA-DNA hybridization was considered the gold standard for decades: genomic hybridization allows for the measurement of the degree of similarity between two genomes; this technique is very useful in the differentiation of closely-related bacterial species $[52,53]$. In contrast, DNA-RNA hybridization is useful in the genetic analysis of two phylogenetically distant bacteria: this is possible, because ribosomal RNA (rRNA) is transfer RNA (tRNA) only represent a minor portion of bacterial genes, which evolves in a slower pace (i.e. they are more conserved), compared to other genes coding for proteins [52,53]. Currently, various nucleic acid sequencing methods (of which, WGS and NGS are one of the most modern) represent the top-tier methods for bacterial classification and the comparison of genomic structures [48-50]. Nucleic acid (DNA and RNA) sequencing is another mo- lecular characteristic that helps directly compare the genomic structures. The sequencing of $5 \mathrm{~S}$ rRNA (from the 50S prokaryotic ribosomal subunit), 16S rRNA and 16S rDNA (from the 305 prokaryotic ribosomal subunit) has received the most substantial attention [47-50]. In fact, current recommendations state that for the submission of a novel species, the performance of MLST or sequencing (to characterize genomic relatedness) and the submission of a preferably full-length $16 \mathrm{~S}$ rRNA gene sequence are recommended [47].

Nevertheless, it is now well-known that the phenotypic as well as the genotypic characteristics of bacteria may be subject to change due to exogenous genetic material (i.e. conjugation, transformation and transduction), which entails the transfer of plasmid DNA from one species/genus/family of bacteria to another. In reality, these properties may also be useful to characterize relations between different bacterial taxa [47-50]. E. coli species conjugate well with Salmonella and Shigella species (which are more closely related taxonomically), but not with members of the genera Proteus, Providencia or Enterobacter. Similar results were found in transformation studies on Rhizobium, Micrococcus, Bacillus and Haemophilus species, showing that transformation events more frequently occur with different species of the same genera (smaller genomic variation), compared to species of different genera (larger genomic variation) [4750].

Table III Examples of bacterial species undergone taxonomic revisions in the last 20-year period

\begin{tabular}{c|c}
\hline \multicolumn{1}{c}{ Previous taxonomic designation } & Current taxonomic designation \\
\hline Actinobaculum schaali & Actinotignum schaali \\
\hline Actinobacillus actinomycetemcomitans & Aggregatibacter actinomycetemcomitans \\
\hline Bacteroides forsythus & Tannerella forsythia \\
\hline Bacteroides gracilis & Prevotella melaninogenica \\
\hline Bacteroides melaninogenicus & Dialister pneumosintes \\
\hline Bacteroides pneumosintes & Borelliella burgdorferi \\
\hline Borellia burgdorferi & Clostridioides difficile \\
\hline Clostridium difficile & Cronobacter shakazakii \\
\hline Enterobacter shakazakii & Klebsiella aerogenes \\
\hline Enterobacter aerogenes & Pluralibacter gergoviae \\
\hline Enterobacter gergoviae & Lelliottia amnigena \\
\hline Enterobacter amnigenus & Eggerthella lenta \\
\hline Eubacterium lentum & Parvimonas micra \\
\hline Klebsiella pnuemonaie ATCC 700603 & Cutibacterium acnes \\
\hline Peptostreptococcus micros & S. oralis subsp. tigurinus \\
\hline Propionibacterium acnes & Camplyobacter rectus \\
\hline Streptococcus tigurinus & \\
\hline Wolinella rectus & quasipneumoniae subsp. similipneumoniae \\
\hline
\end{tabular}




\section{Practical relevance of taxonomical changes}

After the official recognition and acknowledgement of taxonomic alterations or a revised nomenclature, significant changes may occur in the everyday practice of physicians and microbiologists dealing with infectious diseases, epidemiologists, university educations and other relevant stakeholders [47]. Changes in bacterial taxonomy, and nomenclature is usually greeted with conservatism and resistance among taxonomists, microbiologists, healthcare-professionals and scientist alike, for the simple reason that nobody likes change $[1-3,21,47]$. The applications of taxonomic changes can be broad ranging: they may impact the clinical care of patients, through variations in choosing the appropriate antimicrobial susceptibility testing standards or data interpretation, or even their clinical relevance and epidemiology (commensal/colonizer/pathogen). These changes also affect companies supplying laboratories with testing equipment and software (i.e. the laboratory information system or LIS) and even administrative stakeholders (e.g., accreditation services, conformity with legal documentation); of course, the clinical relevance of these changes is also relative to the isolation frequency and invasiveness of the abovementioned bacteria $[33,36,37,43,44,47]$. Some recent changes of interest in bacterial taxonomy are discussed below and presented in Table III.

Gram-negative bacteria (especially ones representing gut bacteria) have seen a plethora of taxonomic revisions since the beginning of the $21^{\text {st }}$ century. Among other things, some Vibrio species have been reclassified into the genera Photobacterium (e.g., P. damselae) and Grimontia (G. hollisae), and the phylogenetically heterogenous members of the E. cloacae complex has been reassigned to the genera Kosakonia, Lelliottia, and Pluralibacter [54-56]. Another relevant change was the one affecting the genus Salmonella, where only Salmonella enterica strains remained in the species status, while other serovariants (e.g., Enteritidis, Typhimurium, Typhi) are no longer recognized on the species level, therefore their names should no longer be italicized [6,57]. However, one of the major taxonomical changes affecting Gram-negative bacteria (and subsequently, the medical community) is the recent reclassification of the family Enterobacteriaceae into the order Enterobacterales, containing seven distinct families (namely Enterobacteriaceae, Erwiniaceae, Pectobacteriaceae, Yersinia- ceae, Hafniaceae, Morganellaceae and Budiviciaceae) based on recent phylogenetic analyses [58]. Other suggestions include the differentiation of all Burkholderia species into two distinct groups: the genus Burkolderia would contain the human pathogenic species, while a newly designated genus Paraburkholderia would hold the non-pathogenic species to humans [59]. In contrast, it was proposed that the genera Chlamydia and Chlamydophila (containing C. pneumoniae and C. psittaci) should be fused together, eliminating the latter genus in the process [60].

Pronounced taxonomic changes have also occured regarding anaerobic bacteria in the last 3040 years [16]. The restriction of the genus Bacteroides to $B$. fragilis and related species has led to the relclassification and transfer of numerous species to the genera Prevotella and Porphyromonas (based on pigmentation, bile-sensitivity and saccharolytic properties) and the introduction of novel genera [61-64]. Marked changes have also occured in the field of Gram-positive anaerobic cocci with the introduction of novel species, such as Finegoldia, Parvimonas and Peptinophilus, based on phylogenetic analysis [16,65-66]. Eubacterium species were also subject to taxonomic revisions, leading to the introduction of novel genera, such as Slackia, Pseudoramibacter, Mogibacterium, Eggerthella and Cryptobacterium $[16,65]$. Perhaps the most controversial taxonomic revision occured regarding the causative agent of antibiotic-associated diarrhoea and pseudomembranous enterocolitis, namely Clostridium (Clostridioides) difficile, which may be considered as the prime example why taxonomic changes have to be carefully considered [67-68]. After the proposal to restric the genus Clostridium to C. butyricum and other related species, it was found that $C$. difficile was phylogenetically closest to $C$. mangenotii with a $94.7 \%$ similarity, however, this species was located in the family Peptostreptococcaceae [69]. This would have lead to a nomenclature revision of $C$. difficile as Peptoclostridium difficile; however, due to the significance of this pathogen in nosocomial infection and as a public health threat, a lot of energy, time and money was put into the education of the public and healthcare professionals around the globe, regarding the dangers of "C. diff" (as it is colloquially known) and $\mathrm{CDD} / \mathrm{CDAD}$ (C. difficile-associated diarrhea), with educational campaigns, fliers, books and so on [16, 67-69]. The proposed taxonomic change would have put forth issues in this educational 
campaign (a sudden change of " $C$. diff" to " $P$. diff" and CDAD to PDAD and so on); for this reason, the reclassification as $P$. difficile was rejected, instead, a novel genus Clostridioides gen. nov. was proposed for C. difficile (now Clostridioides difficile) and C. magnerotii was also reclassified to this new genus; therefore previously used, colloquial designations for this pathogen (C. diff, $\mathrm{CDD} / \mathrm{CDAD})$ also remained valid $[70,71]$.

\section{Conclusions}

Taxonomy is concerned with the classification of living organisms, which operates in three distinct domains, namely classification, nomenclature and identification. Compared to the taxonomic trends in the $19^{\text {th }}$ century, current methods and technologies allow for more detailed phylogenetic analyses, leading to the description of a tremendous amount of novel bacterial species and the re-classification of several already described bacteria. This 'explosion' in microbial taxonomy (further aided by the developments in bacterial systematics) presents an everyday challenge to medical professionals (e.g., clinical pharmacists, physicians and nurses), pharmaceutical scientists and stakeholders in healthcare. However, the up-todate knowledge on bacterial taxonomy is important as it may significantly impact the everyday practice of these healthcare professionals. This is especially true for scientists who use various bacterial strains for screening of antimicrobial activity of various compounds or utilizing any kind of bacterial model system during laboratory assays. The aim of this paper was to aid the abovementioned healthcare professionals to navigate through the 'maze' of bacterial taxonomy, to aid in finding authentic information regarding the description of taxonomic changes and to present some examples of changes in bacterial taxonomy which proven to be clinically significant.

\section{Acknowledgements}

M.G. was supported by the National Youth Excellence Scholarship [Grant Number NTP-NTFÖ18-C-0225] and the ESCMID Observership Programme.

\section{Competing interests}

The author declares no conflict of interest, monetary or otherwise.

\section{References}

1. Cowan, S.T. Sense and nonsense in bacterial taxonomy. J. Gen. Microbiol. 1971; 67: 1-8. https://doi. org/10.1099/00221287-67-1-1

2. Cowan, S.T. Principles and practice of bacterial taxonomy. Microbiology 1965; 39: 148-158. https://doi. org/10.1099/00221287-39-1-143

3. Kraft, C.S., McAdam, A.J., Carroll, K.C. A Rose by any other name: Practical updates on microbial nomenclature for clinical microbiology. J. Clin. Microbiol. 2017; 55: 3-4. https://doi.org/10.1128/ JCM.02169-16

4. Huang, H., Brooks, B.W., Lowman, R., Carrillo, D. Campylobacter species in animal, food, and environmental sources, and relevant testing programs in Canada. Can. J. Microbiol. 2015; 61: 701-721. https://doi.org/10.1139/cjm-2014-0770

5. Johnson, J.R., Orskov, I., Orskov, F., Goullet, P., Picard, B., Moseley, S.L., Roberts, P.L., Stamm, W.E. O, K, and $\mathrm{H}$ antigens predict virulence factors, carboxylesterase B pattern, antimicrobial resistance, and host compromise among Escherichia coli strains causing urosepsis. J. Infect. Dis. 1994; 169: 119-126. https://doi.org/10.1093/ infdis/169.1.119

6. Brenner, F.W., Villar, R.G., Angulo, F.J., Tauxe, R., Swaminanthan B. Salmonella Nomenclature. J. Clin. Microbiol. 2000; 38: 2465-2467. https://doi. org/10.1128/JCM.38.7.2465-2467.2000

7. Fratamico, P.M., DebRoy C., Liu, Y., Neddleman, D.S., Baranzoni, G.M., Feng, P. Advances in Molecular Serotyping and Subtyping of Escherichia coli. Front. Microbiol. 2016; 7: 644. https://doi. org/10.3389/fmicb.2016.00644

8. Ryan, M.P., O’Dwyer, J, Adley, C.C. Evaluation of the Complex Nomenclature of the Clinically and Veterinary Significant Pathogen Salmonella. Biomed. Res. Int. 2017; 2017: 3782182. https://doi. org/10.1155/2017/3782182

9. Palaniappan, R.U.M., Zhang, Y, Chiu, D., Torres, A., DebRoy, C., Whittam, T.S., Chang, Y.F. Differentiation of Escherichia coli Pathotypes by Oligonucleotide Spotted Array. J. Clin. Microbiol. 2006; 44: 1495-1501. https://doi.org/10.1128/JCM.44.4.14951501.2006

10. Browne-Robins, R.M., Holt, K.E., Ingle, D.J., Hocking, D.M., Yang, J., Tauschek, M. Are Escherichia coli Pathotypes Still Relevant in the Era of WholeGenome Sequencing? Front. Cell Infect. Microbiol. 2016; 6: 141.https://doi.org/10.3389/fcimb.2016.00141

11. Cain, A.J. Deductive and inductive methods in post-Linnaean taxonomy. Proc. Linn. Soc. London 1959; 170: 185-217. https://doi. org/10.1111/j.1095-8312.1959.tb00853.x

12. Parks, D.H., Chuvchina, M., Waite, D.W., Rinke, C., Skarshewki, A., Chaumeil, P.A., Hugenholtz, P. A standardized bacterial taxonomy based on genome phylogeny substantially revises the tree of life. Nat. Biotechn. 2018; 36: 996-1004. https://doi.org/10.1038/ nbt.4229

13. Turnbaugh, P.J., Ley, R.E., Hamady, M., FraserLiggett, C.M., Knight, R., Gordon, J.I. The Human Microbiome Project: exploring the microbial part of ourselves in a changing world. Nature 2007; 449: 804-810. https://doi.org/10.1038/nature06244 
14. Hahn, S.A., Altman, T., Konwar, K.M., Hanson, N.W., Kim, D., Relman, D.A., Dill, D.L., Hallam, S.J. A geographically-diverse collection of $418 \mathrm{hu}$ man gut microbiome pathway genome databases. Sci. Data 2017; 4: 1700035. https://doi.org/10.1038/ sdata.2017.35

15. Almeida, A., Mitchell, A.L., Boland, M., Forster, S.C., Gloor, G.B., Tarkowska, A., Lawley, T.D., Finn, R.D. A new genomic blueprint of the human gut microbiota. Nature 2019; 568: 499-504. https://doi. org/10.1038/s41586-019-0965-1

16. Gajdács, M., Spengler, G., Urbán, E. Identification and Antimicrobial Susceptibility Testing of Anaerobic Bacteria: Rubik's Cube of Clinical Microbiology? Antibiotics 2017; 7: 25. https://doi.org/10.3390/antibiotics6040025

17. Lagier, J.C., Armougom, F., Million, M., Hugon, P., Pagnier, I., Robert, C., Bittar, F., Fournous, G., Gimenez, G., Maraninchi, M., Trape, J.F., Koonin, E.V., La Scola, B., Raoult, D. Microbial culturomics: paradigm shift in the human gut microbiome study. Clin. Microbiol. Infect. 2012; 18: 1185-1193. https:// doi.org/10.1111/1469-0691.12023

18. Lay, J.O. MALDI-TOF mass spectrometry and bacterial taxonomy. Trends Anal. Chem. 2000; 19: 507516. https://doi.org/10.1016/S0165-9936(00)00027-3

19. Garrity. G.M. A New Genomics-Driven Taxonomy of Bacteria and Archaea: Are We There Yet? J. Clin. Microbiol. 2016; 54: 1956-1963. https://doi. org/10.1128/JCM.00200-16

20. Siqueira, J.F. Taxonomic changes of bacteria associated with endodontic infections. J. Endodont. 2003; 29: 619-623. https://doi.org/10.1097/00004770200310000-00001

21. Janda, M.J. Taxonomic update on proposed nomenclature and classification changes for bacteria of medical importance, 2016. Diagn. Microbiol. Infect. Dis. 2017; 88: 100-105. https://doi.org/10.1016/j.diagmicrobio.2017.02.003

22. Bacterio.net database http://www.bacterio.net/number.html (Accessed on: 24th of October, 2019).

23. EZBioCloud Database of Prokaryotic Diversity https://www.ezbiocloud.net/dashboard (Accessed on: 24th of October, 2019).

24. Moore, E.R.B., Mihaylova, S.A., Vandamme, P., Krichevsky, M.I., Dijksoorn, L. Microbial systematics and taxonomy: relevance for a microbial commons. Res. Microbiol. 2010; 161: 430-438. https://doi. org/10.1016/j.resmic.2010.05.007

25. Vandamme, P., Pot, B., Gills, M., de Vos, P., Kersters, K., Swings, J. Polyphasic taxonomy, a consensus approach to bacterial systematics. Microbiol. Mol. Biol. Rev. 1996; 60: 407-438. https://doi.org/10.1128/ MMBR.60.2.407-438.1996

26. de Vos, P., Trüper, H.G. Judicial Commission of the International Committee on Systematic Bacteriology. IXth International (IUMS) Congress of Bacteriology and Applied Microbiology. Minutes of the meetings, 14, 15 and 18 August 1999, Sydney, Australia. Int. J. Syst. Evol. Microbiol. 2000; 50: 22392244. https://doi.org/10.1099/00207713-50-6-2239

27. Gajdács, M., Urbán, E. Epidemiological Trends and Resistance Associated with Stenotrophomonas maltophilia Bacteremia: A 10-Year Retrospective Cohort Study in a Tertiary-Care Hospital in Hungary. Diseases 2019; 31: 41. https://doi.org/10.3390/ diseases7020041
28. International Journal of Systematic and Evolutionary Microbiology https://www.microbiologyresearch.org/content/journal/ijsem (Accessed on: 24th of October, 2019).

29. Lapage SP, Sneath PHA, Lessel EF, Skerman VBD, Seeliger HPR, Clark WA (eds.). International Code of Nomenclature of Bacteria: Bacteriological Code, 1990 Revision. Washington (DC): ASM Press; 1992.

30. Taxonomic Outline of the Bacteria and Archaea (Formerly the Taxonomic Outline of the Prokaryotes) Release 7.7 http://www.taxonomicoutline.org/ content/7/7/ (Accessed on: 24th of October, 2019).

31. Baltrus, D.A. Divorcing strain classification from species names. Trends Microbiol. 2016; 24: 431-439. https://doi.org/10.1016/j.tim.2016.02.004

32. Antonie van Leeuwenhoek Journal of Microbiology https://www.springer.com/journal/10482/aims-andscope (Accessed on: 24th of October, 2019).

33. Janda, M.J. Proposed nomenclature or classification changes for bacteria of medical importance: Taxonomic Update 4. Diagn. Microbiol. Infect. Dis. 2019; 94: 205-208. https://doi.org/10.1016/j.diagmicrobio.2018.12.009

34. Berger, S.A., Edberg, S.C. Microbial nomenclature: A list of names and origins. Diagn. Microbiol. Infect. Dis. 1987; 6: 343-356. https://doi.org/10.1016/07328893(87)90185-4

35. Carl Linnaeus, Species Plantarum. Sweden, 1753.

36. Munson, E., Carroll, K.C. An Update on the Novel Genera and Species and Revised Taxonomic Status of Bacterial Organisms Described in 2016 and 2017. J. Clin. Microbiol. 2019; 57: e01181-18. https://doi. org/10.1128/JCM.01181-18

37. Gajdács, M., Urbán, E. Resistance Trends and Epidemiology of Citrobacter-Enterobacter-Serratia in Urinary Tract Infections of Inpatients and Outpatients (RECESUTI): A 10-Year Survey. Medicina (Kaunas) 2019; 55: 285. https://doi.org/10.3390/medicina55060285

38. Bacterio.net Three-letter code for abbreviations of generic names. http://www.bacterio.net/-abbreviations.html (Accessed on: 24th of October, 2019).

39. Stevens, D.L. Invasive group A streptococcus infections. Clin. Infect. Dis. 1992; 14: 2-11. https://doi. org/10.1093/clinids/14.1.2

40. Gajdács, M. The Concept of an Ideal Antibiotic: Implications for Drug Design. Molecules 2019; 24: 892. https://doi.org/10.3390/molecules24050892

41. Gajdács, M. The Continuing Threat of MethicillinResistant Staphylococcus aureus. Antibiotics 2019; 8: 52. https://doi.org/10.3390/antibiotics8020052

42. Gajdács, M. Burián, K., Terhes, G. Resistance Levels and Epidemiology of Non-Fermenting GramNegative Bacteria in Urinary Tract Infections of Inpatients and Outpatients (RENFUTI): A 10-Year Epidemiological Snapshot. Antibiotics 2019; 8: 143. https://doi.org/10.3390/antibiotics8030143

43. Baron, E.J., Allen, S.D. Should clinical laboratories adopt new taxonomic changes? If so, when? Clin. Infect. Dis. 1993; 16: S449-S450. https://doi. org/10.1093/clinids/16.Supplement_4.S449

44. Mandel, M. New approaches to bacterial taxonomy: perspectives and prospects. Ann. Rev. Microbiol. 1969; 23: 239-274. https://doi.org/10.1146/annurev. mi.23.100169.001323

45. Leber, A.L. (eds.) Clinical Microbiology Procedures Handbook, Fourth Edition. 2016; American Society 
for Microbiology, Washington DC, USA. https://doi. org/10.1128/9781555818814

46. Gajdács, M., Urbán, E. The relevance of anaerobic bacteria in brain abscesses: a ten-year retrospective analysis (2008-2017). Infect. Dis. 2019;, 51: 779-781. https://doi.org/10.1080/23744235.2019.1648857

47. Janda, J.M. Clinical Decisions: How Relevant is Modern Bacterial Taxonomy for Clinical Microbiologists? Clin. Microbiol. Newslett. 2018; 40: 51-57. https://doi.org/10.1016/j.clinmicnews.2018.03.005

48. Wayne, B.D., Coldwell, R.R., Grimont, P.A.D., Kandler, O., Krichesvsky, J.I. et al. Report of the ad hoc committee on reconciliation of approaches to bacterial systematics. Int J Syst Bacteriol. 1987; 166: 463464. https://doi.org/10.1099/00207713-37-4-463

49. Mahato, N.K., Gupta, V., Singh, P., Kumari, R., Verma, H., Tripathi, C., et al. Microbial taxonomy in the era of OMICS: application of DNA sequences, computational tools and techniques. Antonie Van Leeuwenhoek. 2017; 110: 1357-1371. https://doi. org/10.1007/s10482-017-0928-1

50. Colabella, C., Corte, L., Roscini, L., Bassetti, M., Tascini, C., Mellor, J.C., Meyer, W., Robert, V., Vu, D., Cardinali, G. NGS barcode sequencing in taxonomy and diagnostics, an application in "Candida" pathogenic yeasts with a metagenomic perspective. IMA Fungus 2018; 9: 91-105. https://doi.org/10.5598/imafungus.2018.09.01.07

51. Thompson, C.C., Chimetto, L., Edwards, R.A., Swings, J., Stackerbrandt, E., Thompson, F.L. Microbial genomic taxonomy. BMC Genomics 2013; 14: 913. https://doi.org/10.1186/1471-2164-14-913

52. Cho, J.C., Tiedje, J.M. Bacterial Species Determination from DNA-DNA Hybridization by Using Genome Fragments and DNA Microarrays. Appl. Environ. Microbiol. 2001; 67: 3677-3682. https://doi. org/10.1128/AEM.67.8.3677-3682.2001

53. Dong, D., Li, J., Gao, Q., Huang, X., Xu, Y., Li, R. Utilizing RNA/DNA hybridization to directly quantify mRNA levels in microbial fermentation samples. J. Microbiol. Methods 2009; 79: 205-210. https://doi. org/10.1016/j.mimet.2009.09.002

54. Pérez-Catalunia, A., Lucena, T., Tarazona, E., Arahal, D.R., Macián, M.C., Pujalte, M.J. An MLSA approach for the taxonomic update of the Splendidus clade, a lineage containing several fish and shellfish pathogenic Vibrio spp. Syst. Appl. Microbiol. 2016; 39: 361-369. https://doi.org/10.1016/j.syapm.2016.03.010

55. Genus Enterobacter http://www.bacterio.net/enterobacter.html (Accessed on: 24th of October, 2019).

56. Davin-Regli, A., Pagés, J.M. Enterobacter aerogenes and Enterobacter cloacae; versatile bacterial pathogens confronting antibiotic treatment. Front. Microbiol. 2015; 6: 392. https://doi.org/10.3389/ fmicb.2015.00392

57. Tindall, B.J., Grimont, P.A.D., Garrity, G.M., Euzéby, J.P. Nomenclature and taxonomy of the genus Salmonella. Int. J. Syst. Evol. Microbiol. 2005; 55: 521-524. https://doi.org/10.1099/ijs.0.63580-0

58. Genome-based phylogeny and taxonomy of the'Enterobacteriales': proposal for Enterobacteralesord. nov. divided into the families Enterobacte- riaceae, Erwiniaceae fam. nov., Pectobacteriaceae fam. nov., Yersiniaceae fam.nov., Hafniaceae fam. nov., Morganellaceae fam. nov., and Budviciaceae fam. nov. Int. J. Syst. Evol. Microbiol. 2016; 66: 55755599. https://doi.org/10.1099/ijsem.0.001485

59. Coenye, T., Vandamme, P., Govan, J.R.W., LiPuma, J.J. Taxonomy and Identification of the Burkholderia cepacia Complex. J. Clin. Microbiol. 2001; 39: 3427-3436. https://doi.org/10.1128/JCM.39.10.34273436.2001

60. Stephens, R.S., Myers, G., Eppinger, M., Bavoil, P.M. Divergence without difference: phylogenetics and taxonomy of Chlamydia resolved. FEMS Immunology \& Medical Microbiology. 2009; 55: 115-119. https://doi.org/10.1111/j.1574-695X.2008.00516.x

61. Shah HN, Collins MD. Proposal to restrict the genus Bacteroides (Castellani and Chalmers) to Bacteroides fragilis and closely related species. Int. J. Syst. Bacteriol. 1989; 39: 85-87. https://doi. org/10.1099/00207713-39-1-85

62. Shah HN, Collins DM. Prevotella, a new genus to include Bacteroides melaninogenicus and related species formerly classified in the genus Bacteroides. Int. J. Syst. Bacteriol. 1990; 40: 205-8. https://doi. org/10.1099/00207713-40-2-205

63. Shah HN, Collins DM. Proposal for reclassification of Bacteroides asaccharolyticus, Bacteroides gingivalis, and Bacteroides endodontalis in a new genus, Porphyromonas. Int. J. Syst. Bacteriol. 1988; 38: 128131. https://doi.org/10.1099/00207713-38-1-128

64. Jousimies-Somer H, Summanen P. Recent taxonomic changes and terminology update of clinically significant anaerobic gram-negative bacteria (excluding spirochetes). Clin. Infect. Dis. 2002; 35: S17-S21. https://doi.org/10.1086/341915

65. Sumamanen P. Recent Taxonomic Changes for Anaerobic Gram-Positive and Selected Gram-Negative Organisms. Clin. Infect. Dis. 1993; 16: S168-S174. https://doi.org/10.1093/clinids/16.Supplement_4.S168

66. Gajdács, M., Urbán, E., Terhes, G. Microbiological and Clinical Aspects of Cervicofacial Actinomyces Infections: An Overview. Dent. J. 2019; 7: 85. https:// doi.org/10.3390/dj7030085

67. Knight, D.R., Elliott, B., Chang, B.J., Perkins, T.T., Riley, T.V. Diversity and Evolution in the Genome of Clostridium difficile. Clin. Microbiol. Rev. 2015; 28: 721-741. https://doi.org/10.1128/CMR.00127-14

68. Hassoun, A. Clostridium difficile associated disease. BMJ 2018, 363. https://doi.org/10.1136/bmj.k4369

69. Gajdács, M., Paulik, E., Szabó A. [The opinions of community pharmacists related to antibiotic use and resistance] (article in Hungarian). Acta Pharm. Hung. 2018; 88: 249-252.

70. Luo, Y., Hunag, C., Ye, J., Fang, W., Gu, W., Chen, Z., Li, H., Wang, X.J., Jun, Dazhi L. Genome Sequence and Analysis of Peptoclostridium difficile Strain ZJCDC-S82. Evol. Bioinform. 2016; 12: 41-49. https:// doi.org/10.4137/EBO.S32476

71. Lawson, P.A., Citron, D.M., Tyrrell, K.L., Finegold, S.M. Reclassification of Clostridium difficile as Clostridioides difficile (Hall and O'Toole 1935) Prévot 1938. Anaerobe 2016; 40: 95-99. https://doi. org/10.1016/j.anaerobe.2016.06.008 